\title{
PREDIKSI HARGA KOMODITI JAGUNG MENGGUNAKAN K-NN DAN PARTICLE SWARM OPTIMAZATION SEBAGAI FITUR SELEKSI
}

\author{
Mohamad Efendi Lasulika \\ fendilasulika123@gmail.com \\ Program Studi Teknik Informatika, Universitas Ichsan Gorontalo
}

\begin{abstract}
Abstrak
Jagung merupakan komponen makanan utama di dunia, terutama di daerah tropis. Ketidaktetapan harga produk pertanian akan mengakibatkan ikut turun naiknya pendapatan yang diterima oleh petani dari hasil produksi pertanian mereka. Salah satu upaya untuk mengantisipasi terjadinya ketidaktetapan harga adalah dengan melakukan peramalan harga. Peramalan harga dimaksudkan untuk melakukan prakiraan/prediksi harga masa depan dalam kurun waktu tertentu, dengan hasil keluaran berupa harga masa depan.Metode K-NN dapat digunakan untuk memprediksi harga komoditi. Hasil eksperiment yang telah dilakukan peneliti menunjukkan bahwa algoritma K-NN berbasis Particle Swarm Optimazation lebih baik dibandingkan dengan algoritma K-NN tanpa fitur seleksi. Berdasarkan hasil penelitian nilai RMSE terendah terdapat pada K-Nearest Neighbor berbasis Particle Swarm Optimazation untuk data jagung dengan variabel periode 4 parameter k 7 nilai population 5 Max Of Generation 40 dengan nilai RMSE 0,06
\end{abstract}

\section{Kata Kunci: Time Series, K-Nearest Neighbor, Particle Swarm Optimazation}

\section{Pendahuluan}

Kebutuhan akan komoditas jagung untuk bahan pangan, bahan pakan serta bahan baku industri terus meningkat. Semakin meningkatnya volume impor jagung cukup beralasan mengingat harga jagung impor relative rendah dibandingkan harga jagung di pasar domestik, disertai terjaminnya kualitas produk, di sisi lain pertumbuhan produksi jagung indonesia masih agak lamban akibat masih rendahnya tingkat produktivitas dan areal pertanaman sehingga menyebabkan terjadinya ketidakseimbangan antara produksi dan permintaan dalam negeri. Mencermati perkembangan harga internasional dan dalam upaya meningkatkan daya saing jagung di pasar domestik maupun pasar luar negeri, pemerintah perlu menerapkan strategi kebijakan perdagangan yang efektif, sehingga mampu mewujudkan ketersediaan pasokan komoditas jagung dan pengamanan harga jagung di tingkat petani. Banyaknya produksi jagung yang diperdagangkan di pasar dunia dan kecenderungan menurunnya harga jagung di pasar dunia menuntut kebijakan pemerintah yang seksama dalam mengendalikan stabilisasi harga jagung domestik [1].

Di sektor pertanian, setiap aktivitas proses produksi selalu dihadapkan dengan situasi resiko (risk) dan ketidakpastian (uncertainty). Sumber ketidakpastian yang penting di sektor pertanian adalah ketidaktetapan hasil pertanian dan harga. Ketidaktetapan harga produk pertanian akan mengakibatkan ikut turun naiknya pendapatan yang diterima oleh petani dari hasil produksi pertanian mereka. Hal ini mengakibatkan semakin tingginya resiko yang diterima oleh para pelaku usaha tani ketika berinvestasi pada sektor pertanian, pentingnya sektor pertanian sebagai pemasok kebutuhan pangan penduduk inilah yang mengakibatkan pemerintah di banyak negara melakukan stabilisasi harga produk pertanian untuk meminimalikan terjadinya ketidaktetapan harga produk pertanian [2].

Salah satu upaya untuk mengantisipasi terjadinya fluktuasi harga adalah dengan melakukan peramalan harga. Peramalan harga dimaksudkan untuk melakukan prakiraan/prediksi harga masa depan dalam kurun waktu tertentu, dengan hasil keluaran berupa harga masa depan. Peramalan harga ditujukan untuk mendapatkan gambaran tentang keadaan yang akan terjadi di masa yang akan datang agar dapat digunakan untuk melakukan pengambilan keputusan terkait, guna meminimalisasi resiko dan memaksimalkan potensi keuntungan yang dapat diraih. Peramalan merupakan pendugaan akan suatu hal dimasa yang akan datang, kebutuhan peramalan timbul karena adanya jeda waktu antara satu hal atau peristiwa dengan kebutuhan mendatang. Adapun permasalahan yang dihadapi yaitu sulitnya memprediksi harga jagung yang berubah-ubah setiap minggunya, dan padapenelitian yang dilakukan oleh Anto [3] menggunakan model Backpropagation Neural Network berbasis Forward Selectionmasih menghasilkan nilai RMSE yang besar, pada penelitian ini menunjukan bahwa Penentuan nilai parameter yang digunakan pada backpropagation neural network sangat berpengaruh pada rmse yang dihasilkan. Adapun tujuan penelitian ini adalah Penerapan Metode K-NN dan PSO 
agar dapat menghasilkan nilai error yang lebih kecil sehingga memudahkan untuk prediksi harga komoditi jagung setiap minggunya

\section{Metode Penelitian}

\subsection{Data Mining}

Data mining sebagai proses untuk mendapatkan informasi yang berguna dari gudang basis data yang besar. Salah satu teknik yang dibuat dalam data mining adalah bagaimana menelusuri data yang ada untuk membangun sebuah model, kemudian menggunakan model tersebut agar dapat mengenali pola data yang lain yang tidak berada dalam basis data yang tersimpan [4].

\subsection{Time Series}

Time series adalah suatu rangkaian atau seri dari nilai-nilai suatu variable atau hasil observasi, dalam hal ini adalah nilai indeks harga saham dalam janga waktu yang berurutan [5]. Metode time series adalah metode peramalan dengan menggunakan analisa pola hubungan antara variabel yang akan diperkiran dengan variabel waktu atau analisis time series.

\subsection{K-Nearest Neighbor}

Algoritma K-NN merupakan metode Algoritma supervised learningyang tujuannya untuk mendapatkan pola baru sedangkan unsupervised learning tujuannya untuk mendapatkan pola dalam sebuah data [6].Prinsip kerja K-Nearest Neighbor (K-NN) adalah mencari jarak terdekat antara data yang akan dievaluasi dengan $\mathrm{K}$ tetangga (neighbor) terdekatnya dalam data pelatihan. Data training diproyeksikan ke ruang berdimensi banyak, yang mana masing-masing dimensi menjelaskan fitur dari data [7].Dalam melakukan prediksi harga komoditi jagung dengan menggunakan algoritma KNN digunakan model sebagai berikut :

Keterangan:

$$
D=\sqrt{\left(x_{1}-y_{1}\right)^{2}+\left(x_{2}-y_{2}\right)^{2}}
$$

$\mathrm{x}=$ sampel data

$\mathrm{y}=$ data uji

$\mathrm{D}=$ Jarak

Dengan $\mathrm{D}$ adalah jarak antara titik pada data training $\mathrm{x}$ dan titik data testing $\mathrm{y}$ yang akan diklasifikasi, dimana $\mathrm{x}=\mathrm{x} 1, \mathrm{x} 2, \ldots, \mathrm{xi}$ dan $\mathrm{y}=\mathrm{y} 1, \mathrm{y} 2, \ldots, \mathrm{yi}$ dan I merepresentasikan nilai atribut serta $\mathrm{n}$ merupakan dimensi atribut.

Langkah-langkah untuk menghitung metode Algoritma K-Nearest Neighbor [8]:

a. Tentukan jumlah $\mathrm{K}=$ Jumlah tetangga terdekat.

b. Hitung jarak antara data baru dengn semua data training

c. Urutkan jarak tersebut dan tetapkan tetangga terdekat berdasarkan jarak minimu ke-K

d. Periksa kelas dari tetangga terdekat

e. Gunakan mayoritas sederhana dari kelas tetangga terdekat sebagai nilai prediksi data baru

\subsection{Feature Selection}

Feature selection (pemilihan fitur) adalah sebuah proses yang biasa digunakan dalam machine learning dimana sekumpulan dari fitur yang dimiliki oleh data digunakan untuk pembelajaran algoritma.

\subsection{Particle Swarm Optimazion}

Particle swarm optimization, disingkat sebagai PSO, didasarkan pada perilaku sebuah kawanan serangga, seperti semut, rayap, lebah atau burung. Algoritma PSO meniru perilaku sosial organisme ini [9].Pencarian solusi optimal dalam PSO akan dilakukan sampai semua partikel memiliki skema solusi yang sama atau ketika iterasi tertinggi telah tercapai.

Velocity pada metode PSO dituliskan sebagai berikut:

$$
\begin{aligned}
& v i, d=w * v i, d+c 1 * R *(\text { pbesti, } d-x i, d)+v c 2 * R *(g b e s t d-x i, d) \\
& \text { dan pehitungan posisinya : } \\
& x i d=x i, d+v i, d \\
& \begin{array}{ll}
\text { dimana : } \\
V i, d & =\text { Kecepatan partikel ke-i pada iterasi ke-i } \\
w & =\text { Bobot inersia } \\
c 1, c 2 & =\text { Konstanta akeselerasi (learning rate }) \\
R & =\text { Bilangan random }(0-1) \\
x i, d & =\text { Posisi saat ini dari partikel ke-i pada iterasi ke-i } \\
\text { pbesti } & =\text { Posisi terbaik sebelumnya dari partikel ke-i }
\end{array}
\end{aligned}
$$


gbestd = Partikel terbaik diantara semua partikel dalam satu koloni

$n \quad=$ Jumlah partikel dalam koloni

d $\quad=$ Dimensi

langkah-langkahalgoritma PSO:

a. Atur parameter $X$

b. untuk setiap $x_{i} \in X$

c. evaluasi fitness dengan menggunakan posisi $x_{i}(t)$ dan fungsi fitness $f$

d. bandingkan fitness $x_{i}$ dengan fitness yang terbaik; jika $f\left(x_{i}(t)\right)>f\left(P_{\text {ibest }}\right)$, Kemudian

$$
P_{\text {ibest }}=x_{i}(t) \operatorname{dan} f\left(P_{\text {ibest }}\right)=f\left(x_{i}(t)\right)
$$

e. bandingkan fitness $x_{i}$ dengan global fitness terbaik sehingga: Jika

$$
f\left(x_{i}(t)\right)>f\left(g_{\text {best }}\right), \text { maka }_{\text {best }}=x_{i}(t) \text { dan } f\left(g_{\text {best }}\right)=f\left(x_{i}(t)\right)
$$

f. hitung kecepatan pada saat berikutnya $x_{i}$ menurut

$$
v_{i}(t+1)=W \cdot v_{i}(t)+c_{1} \psi_{1}\left(P_{\text {ibest }}-x_{i}(t)\right)+c_{2} \psi_{2}\left(g_{\text {ibest }}-x_{i}(t)\right)
$$

g. pindahkan $x_{i}$ ke posisi baru menggunakan persamaan

$$
x_{i}(t+1)=x_{i}(t)+v_{i}(t+1)
$$

h. lanjutkan ke langkah 2 sampai kriteria berhenti.

\subsection{K-Fold Cross Validation}

$K$-fold cross validation merupakan salah satu metode yang digunakan untuk mengetahui ratarata keberhasilan dari suatu sistem dengan cara melakukan perulangan dengan mengacak atribut masukan sehingga sistem tersebut teruji untuk beberapa atribut input yang acak. K-Fold Cross Validation merupakan teknik validasi yang membagi data ke dalam $k$ bagian dan kemudian masingmasing bagian akan dilakukan proses klasifikasi.

\subsection{Data penelitian}

Sumber data pada penelitian ini diambil dari data set Badan Pengawasan Perdagangan Berjangka Komoditi (BAPPEBTI). Data yang diperoleh adalah data harian time series univariate, data tersebut berupa data harga komoditi jagung/kg dari tahun 2010-2015 dengan jumlah record 1435 . Data tersebut untuk hari sabtu dan minggu tidak terjadi transaksi serta tanggal merah setiap tahunnya kosong dan terdiri dari variabel harga.Preprocessing data yang dilakukan pada penelitian ini menggunakan normalisasi data. Normalisasi data digunakan untuk mengelompokkan data ke dalam skala atau jangkauan tertentu sehingga mempermudah dalam mengolah data. Data yang ada masih berupa univariate, sehingga perlu di ubah lagi menjadi multivariate, sehingga menjadi beberapa variabel independent.Pada tahap evaluasi ini, nilai yang dihasilkan dari pengujian berupa nilai Root Mean Square Error (RMSE), nilai RMSE yang kecil menunjukkan hasil akurasi prediksi yang terbaik. Rumus RMSE dipresentasikan dengan persamaan :

RMSE $=\sqrt{\frac{\sum_{t=l}^{n}\left(\mathbf{X}_{\mathrm{t}}-\mathrm{F}_{\mathrm{t}}\right)^{2}}{n}}$

$\mathrm{Xt}=$ nilai aktual pada periode $\mathrm{ke} t$

$\mathrm{Ft}=$ nilai peramalan pada periode ke $\mathrm{t}$

$\mathrm{Xt}-\mathrm{Ft}=$ nilai kesalahan (error) pada periode ke $\mathrm{t}$

$\mathrm{N}=$ jumlah data

\section{Hasil dan Pembahasan}

\subsection{Pengolahan Data}

Proses awal sebelum dilakukan pengujian menggunakan metode K-NN dan PSO yaitu tahap Preprocessing. Tahap preprocessing data yang digunakan pada penilitian ini adalah normalisasi data.

Tabel 1. Hasil Normalisasi

\begin{tabular}{lll}
\multicolumn{1}{c}{ Minggu } & \multicolumn{2}{c}{ Harga } \\
\hline Minggu Ke & 1 & 0,106584886 \\
\hline Minggu Ke & 2 & 0,100104155 \\
\hline Minggu Ke & 3 & 0,093739151 \\
\hline Minggu Ke & 4 & 0,092697604 \\
\hline Minggu Ke & 5 & 0,091308876 \\
\hline Minggu Ke & 6 & 0,091771786
\end{tabular}




\begin{tabular}{lcc}
$\ldots \ldots \ldots$ & $\ldots$ & $\ldots \ldots$ \\
\hline Minggu Ke & 305 & 0,037032751 \\
\hline
\end{tabular}

\subsection{Hasil Pengujian K-NN}

Hasil dari semua percobaaan yang telah dilakukan untuk menentukan model terbaik dari KNearest Neighbor, dari periode 1-8 periode dimana uji coba dilakukan dengan nilai K-Fold cross validation $=10$, serta menentukan nilai dari Parameter $\mathrm{K}$ antara 1,3,5 dan 7. Berikut adalah rangkuman dari hasil uji coba model terbaik dari pada setiap periodenya.

Tabel 2 Hasil Pengujian K-NN

\begin{tabular}{cccc}
\hline Periode & $\begin{array}{c}\text { K- Fold } \\
\text { Cros } \\
\text { Validation }\end{array}$ & $\begin{array}{c}\text { Parameter } \\
\boldsymbol{k}\end{array}$ & RMSE \\
\hline $\mathbf{1}$ & 10 & 7 & 0,07 \\
\hline $\mathbf{2}$ & 10 & 7 & 0,069 \\
\hline $\mathbf{3}$ & 10 & 7 & 0,069 \\
\hline $\mathbf{4}$ & 10 & 7 & 0,067 \\
\hline $\mathbf{5}$ & 10 & 7 & 0,074 \\
\hline $\mathbf{6}$ & 10 & 7 & 0,073 \\
\hline $\mathbf{7}$ & 10 & 7 & 0,073 \\
\hline $\mathbf{8}$ & 10 & 7 & 0,072 \\
\hline
\end{tabular}

\subsection{Hasil Pengujian K-NN dan PSO}

Setelah didapatkan nilai RMSE terendah dari model K-NN selanjutnya dilakukan pengujian menggunakan KNN berbasis Particle Swarm Optimazation. Dari hasil pengujian tersebut didapatkan nilai RMSE terendah yaitu 0,06 .

\begin{tabular}{cccccc}
\hline $\begin{array}{c}\text { Topu } \\
\text { lasi }\end{array}$ & $\begin{array}{c}\text { Max of } \\
\text { Genaration }\end{array}$ & $\begin{array}{c}\text { Bobot } \\
\text { Inersia }\end{array}$ & $\begin{array}{c}\text { Bobot } \\
\text { Local } \\
\text { best }\end{array}$ & $\begin{array}{c}\text { Bobot } \\
\text { Global } \\
\text { Best }\end{array}$ & RMSE \\
\hline $\mathbf{5}$ & 10 & 1,0 & 1,0 & 1,0 & 0,065 \\
\hline $\mathbf{5}$ & 20 & 1,0 & 1,0 & 1,0 & 0,063 \\
\hline $\mathbf{5}$ & 30 & 1,0 & 1,0 & 1,0 & 0,061 \\
\hline $\mathbf{5}$ & 40 & 1,0 & 1,0 & 1,0 & 0,06 \\
\hline $\mathbf{5}$ & 50 & 1,0 & 1,0 & 1,0 & 0,061 \\
\hline
\end{tabular}

\subsection{Evaluasi Metode}

Dari hasil percobaan yang dilakukan didapatkan model terbaik nilai Parameter $\mathrm{K} 7$ pada algoritma K-NN dan populasi 5, nilai max of generation 40 , bobot inersia 1,0 local best 1,0 dan gbest 1,0 pada $\mathrm{PSO}$, diperoleh error terkecil senilai 0,06 .

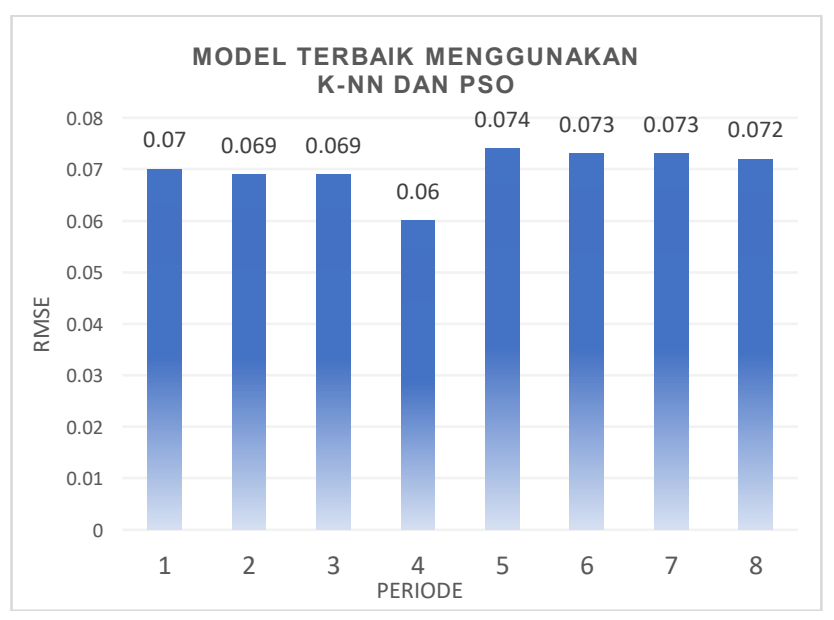

Gambar 1. Grafik model terbaik menggunakan Knn dan PSO 


\subsection{Hasil Prediksi Harga Jagung}

Setelah mendapatkan model terbaik yang didapatkan dari eksperiment yang telah dilakukan oleh peneliti selanjutnya mengimplementasikan data set sebanyak 4 record untuk prediksi harga komoditi jagung selama 4 minggu ke depan.

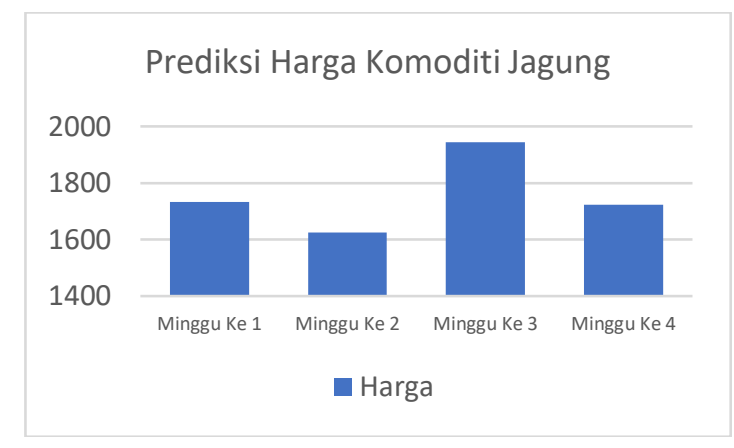

Gambar 2. Hasil Prediksi Harga Jagung

Berdasarkan Gambar di atas dapat dilihat prediksi kisaran harga jagung untuk empat minggu kedepan bulan januari tahun 2016. Dari hasil prediksi yang dilakukan peneliti, maka apabila dibandingkan dengan hasil komoditi harga jagung yang di dapatkan dari Bappebti untuk harga empat minggunya di bulan januari tahun 2016, dapat dilihat pada gambar berikut ini :

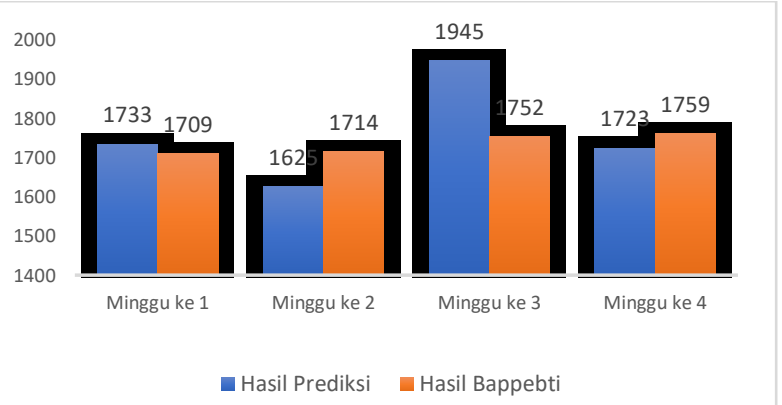

Gambar 5. Perbandingan Hasil Prediksi dan Hasil Bappebti

Dari gambar tersebut dapat dilihat bahwa hasil prediksi harga komoditi jagung tidak berbeda jauh dengan harga jagung dari Bappebti dengan tingkat keakuratan yang didaptkan dari metode dalam memprediksi yaitu sebesar 98,7 \%, dan perbedaan selisihnya sekitar 1,3\%. Prediksi harga jagung selama empat minggu pada tahun 2016 berkisar Rp. 1600 hingga Rp. 1900 per kilogram. Kisaran ini hampir sama dengan harga jagung dari Bappebti yaitu sekitar Rp 1700 per kilogram.

\section{Kesimpulan dan Saran}

Dengan menambahkan fitur seleksi pada algoritma K-NN dapat meningkatkan kinerja dari algoritma tersebut, dari hasil yang telah dilakukan menunjukkan bahwa Algoritma K-NN berbasis Particle Swarm Optimazation lebih baik dibandingkan dengan algoritma K-NN tanpa fitur seleksi. Penentuan nilai parameter $\mathrm{K}$ yang digunakan pada K-NN sangat berpengaruh pada RMSE yang dihasilkan dengan nilai RMSE 0,06 dan tingkat keakuratan metode dalam memprediksi sebesar 98,7 \%.Perbandingan harga antara hasil prediksi tidak berbeda jauh dengan harga komoditi yaitu berkisar Rp. 1600 hingga Rp. 1900 per kilogram sementara hasil komoditi sekitar Rp. 1700 perkilogram.

Saran pada tahap peneitian selanjutnya dapat menggunakan pendekatan komputasi cerdas lainnya untuk melakukan prediksi harga komoditi jagung.

\section{Daftar Pustaka}

[1]. Rachman Benny, Dinamika Harga dan Perdagangan Komoditas Jagung, Bogor. 2011

[2]. Simanungkalit Jubelitor Ferlando, Sistem pendukung keputusan berbasis jaringan saraf tiruan untuk peramalan harga komoditas tanaman pangan. Yogyakarta, Jurnal Agritech, Vol. 33, No. 1 Februari 2013, 
[3]. Anto, Prediksi time series harga komoditi kakao dan jagung dengan Algoritma Backpropagation Neural Network berbasis Forward Selection, Semarang, 2013

[4]. Prasetyo Eka, Data Mining Konsep dan Aplikasi Menggunakan Matlab, CV. Andi Offset, Yogyakarta, 2012

[5]. Yanti Novi, Penerapan Metode Neural Network dengan struktur Backpropagation untuk prediksi Stok Obat di Apotek, Seminar Nasional Aplikasi Teknologi Informasi, ISSN : 1907-5022, 2011

[6]. Pandie S.Y. Emerensye, Implementasi Algoritma Data Mining K-Nearest Neighbor(K-NN) Dalam Pengambilan Keputusan Pengajuan Kredit, Seminar Nasional Sains dan Teknik, Kupang. 2012

[7]. R. N. Whidhiasih, N. A. Wahanani and Supriyanto, Klasifikasi buah belimbing berdasarkan citra red-greenblue menggunakan knn dan Ida, Jurnal Penelitian IImu Komputer, System Embedded \& Logic 1(1) : 29-35, 2013

[8]. Imandoust Bafandeh S, dkk, Application of K-Nearest Neighbor (KNN) Approach for Predicting Economic Events : Theoretical Background, S.B Imandoust et al. Int. Journal of Engineering Research and Applications. Vol. 3, Issue 5, 2013

[9]. Utami nanik. Aplikasi Metode iParticle Swarm Optimazationdalam Clustering (Studi Kasus : Penentuan Karakteristik Segmentasi Pasar Pulsa Di Surabaya Timur, Surabaya 